Strahlenther Onkol 2013 · 189:105-110

DOI 10.1007/s00066-012-0299-5

Published online: 10. Januar 2013

๑) Springer-Verlag Berlin Heidelberg 2013

M.L. Sautter-Bihl ${ }^{1} \cdot$ W. Hohenberger ${ }^{2} \cdot$ R. Fietkau ${ }^{3} \cdot$ C. Rödel $^{4} \cdot$ H. Schmidberger ${ }^{5}$. R. Sauer ${ }^{3}$

${ }^{1}$ Klinik für Radioonkologie und Strahlentherapie, Städtisches Klinikum Karlsruhe

${ }^{2}$ Chirurgische Klinik, Universitätsklinikum Erlangen

${ }^{3}$ Strahlenklinik, Universitätsklinikum Erlangen

${ }^{4}$ Klinik für Strahlentherapie, Klinikum der Johann Wolfgang Goethe-Universität Frankfurt a.M.

${ }^{5}$ Klinik und Poliklinik für Radioonkologie und Strahlentherapie,

Klinik der Johann Gutenberg Universität, Mainz

\title{
Rectal cancer
}

\section{When is the local recurrence risk low enough to refrain from the aim to prevent it?}

tempts in the German-speaking community such as the OCUM study (optimized surgery and MRI-based multimodal therapy of rectal cancer). Preliminary results were recently published $[22,42]$ and are commented in this editorial.

Altogether, 230 patients with rectal cancer clinically staged as cT2 -4 , any cN, cM0 were included in this observational study. The anticipated CRM assessed by MRI (mrCRM) was used as a decision tool for selecting patients $(\mathrm{n}=230)$ either to undergo primary surgery $(n=134)$ or to receive nRCT $(n=96)$. For the lower third of the rectum (defined as $<6 \mathrm{~cm}$ from the anal verge, $37 \%$ ), nRCT was performed in all cT3 and cT4 tumors, irrespective of the anticipated CRM status; tumors of the middle third (i.e., 6 to $<12 \mathrm{~cm}$ ) were treated by $\mathrm{nRCT}$ in case of positive mrCRM only. For the upper third $(12-16 \mathrm{~cm})$, the decision was left to the discretion of the treating center. Clinically positive lymph nodes did not influence the choice of therapy; in patients with pathologically positive lymph nodes, chemotherapy was offered according to the standard of the respective centers. Postoperative RCT was restricted to patients with an involved CRM (pCRM $\leq 1 \mathrm{~mm}$ ) [42].

The mrCRM was positive in $74 / 230 \mathrm{pa}-$ tients, 72 in the nRCT group and 2 of the patients selected for surgery alone. A pathologically positive CRM (pCRM) occurred in $5.7 \%$ of all patients (nCRT: $11 \%$, primary surgery: $1.5 \%$ ). Pathology re- vealed complete remission (ypT0N0) after nRCT in $15 \%$ of patients, a partial remission in $67 \%$. Even in patients whose margins were involved on MRI, pathology reported a negative CRM in $86 \%$ after nRCT. Down-categorization of the primary tumor ( $\mathrm{T}$ category) was observed in $62 \%$ of patients, for lymph nodes in $88 \%$. Acute side effects (grade III) of nRCT were stomatitis (7.4\%), diarrhea (4.9\%), proctitis $(2.4 \%)$, and nausea (3.7\%). Postoperative complications were $20 \%$ after nRCT versus $23.5 \%$ after surgery alone. The authors concluded

Despite the negative selection of locally advanced rectal cancer cases for $n R C T$, impressive rates of tumor downstaging and eradication of tumor from the mesorectal fascia were achieved. Moreover, this selective use of nRCT spared a considerable percentage of patients with stage II/III rectal cancer severe irradiation toxicity [22].

\section{What is an acceptable rate of local recurrence?}

It is beyond dispute that unnecessary costs and toxicity should be minimized; however, the question remains to what extent this potential sparing is justified at the expense of an increased LR risk - in relation to the achievable local control. Summarizing the results from recent randomized trials, the addition of radiotherapy to the multimodal concept provides a 5-year loging $[23,43]$ and promoted similar at- 
coregional recurrence rate (LRR) of only of $5-8 \%$ and $<5 \%$ in low risk rectal cancer [37, 40, 45]. In our opinion, this range should be defined as an obliging benchmark for selecting patients with an assumed low risk of LR for surgery alone. A similar threshold is suggested by Glimelius [11] who regards an expected LRR of "less than 10 percent" (i.e., $10 \%$ is too much!) as appropriate to qualify for a "favourite risk group" that may justify omission of radiotherapy. Under these assumptions, several requirements result for clinical studies:

- the 5-year local recurrence rate is the decisive endpoint for estimating the relevance of data from clinical studies proposing surgery alone in stage II/III patients. Surrogate parameters, such as a negative CRM, cannot replace this endpoint;

- the noninferiority of surgery alone can not be presumed unless the expected 5-year LRR is $\leq 5-8 \%$, whereas any excess of this range renders the study design inacceptable;

- unless a publication explicitly specifies 5-year LRR (as in the commented papers) [22, 42], results are not exploitable for clinical decisions; and

- the omission of radiotherapy needs to be explored in a radomized trial before recommendations for treatment can be adopted into clinical practice.

\section{Can MRI predict prognosis?}

Striving for a more risk-adapted use of nRCT, Hermanek et al. [18] published a proposal for an MRI-guided treatment decision on the basis of a risk estimation for local recurrence in stage II/III patients after guideline-adherent versus MRIbased selection for nCRT. He assumed a local recurrence rate (LRR) of $6 \%$ after "conventional nRCT", according to the data of the CAO/ARO/AIO-94 trial [37]. For MRI-based treatment he calculated a 5\% increase of the absolute risk of LR for "best case", i.e., specialized centers and $12 \%$ in "worst case", i.e., institutions with lower quality of MRI and less expertise in terms of achieving an optimal plane of surgery.

The attempt to use MRI to optimize preoperative diagnostic work-up was extensively investigated by the MERCURY study group who demonstrated the diagnostic accuracy of MRI in patients who were either primarily operated or underwent nRCT according to the predicted CRM $[29,43]$. They provided the first publication of 5-year data correlating mrCRM and LRR with surgery alone. Of 374 patients followed up in the MERCURY study, 122 were preoperatively diagnosed as "good prognosis group" if the following criteria were met: a negative CRM predicted in MRI, no evidence of extramural venous invasion, as well as an early T-category, i.e., T2/T3a/T3b (no perirectal fat invasion or $<5 \mathrm{~mm}$ spread from muscularis propria). The MRI lymph node status was not taken into account to define the "good prognosis group". Moreover, 57 of those 122 patients (47\%) had clinical stage I tumor and would not have received nRCT according to current guidelines anyway, and 40 patients (33\%) had tumors in the upper third of the rectum. The remaining 65 patients of those $122 \mathrm{pa}$ tients accounted for stage cII $(n=43) / c I I I$ $(n=22)$. All patients underwent primary surgery, pathologic work-up showed a confirmation of the predicted CRM-negativity in $96.7 \%$. Noteworthy, only the absolute numbers of locoregional recurrences were published instead of the actuarial 5 -year rates. In the whole group, the LRR was $3 \%$ and the 5 -year disease-free survival (DFS) 85\%. However, 5-year overall survival (OAS) was only $68 \%$. Interestingly, the median age was 69.5 years, suggesting that a percentage of the patients died before LR became clinically apparent. In any case, the quantity of only 65 patients with stage II and III disease being relevant for the question (among those also patients with upper rectal cancer!) whether the conventionally indicated radio(chemo) therapy can be safely omitted is too small to draw any reliable conclusions. Thus, despite promising results, this analysis does not provide unequivocal evidence for the appropriateness of using $\mathrm{mrCRM}$ as a sole criterion for further treatment choice.

\section{Does CRM predict futility of further treatment?}

In this regard it is interesting to analyze the LRR of a "risk adapted treatment" published to date, such as the British-Canadian multicentre study (MRC C07 and NCIC-CTG C016) [40] that investigated the effect of omitting radiotherapy. Overall, 1350 patients with resectable rectal cancer (stage I-III) were randomized for either preoperative RT or primary surgery with "selective" postoperative RCT, the latter restricted to only those patients whose pathology revealed a distance between tumor and mesorectal fascia of $<1 \mathrm{~mm}$, i.e., a positive circumferential resection margin. MRI was not routinely performed and formal training for surgeons had not yet been implemented. Nonetheless, a negative CRM was achieved in $89 \%$. Of the 676 patients randomized for primary surgery, 77 (12\%) had a positive CRM, 53 patients received RCT, and 7 patients RT alone; additional adjuvant ChT was used in $40 \%$ with stage cIII in both arms. Patients with preoperative RT had a significantly better 3-year disease-free survival (DFS; 77.5\% vs. $71.5 \%, \mathrm{p}=0.013$ ) and a significantly lower 3 -year LRR (4.4\% vs. $10.6 \%, \mathrm{p}<0.0001)$. Moreover, those patients with a negative CRM had a 3-year LRR of $8.9 \%$ in the primary surgery group vs. only $3.3 \%$ in the preoperatively irradiated patients, indicating that preoperative RT is particularly effective when surgery is optimal and the circumferential margin is negative. Interestingly, Quirke et al. [31], one of the protagonists of the MERCURY project, analyzed the impact of the plane of surgery in the above described trial [40] and found that, in multivariate analysis, CRM was not predictive for LR.

Additional information about the impact of treatment in relation to CRM can be derived from the 12-year follow-up analysis of the Dutch randomized TME trial [45]. Especially those $81 \%$ of patients with a pathologically negative CRM experienced benefit from preoperative RT: a reduced 10-year LRR was observed throughout all stages $(\mathrm{p}<0.0001)$ :

- stage cI: $1 \%$ vs. $3 \%$,

- stage cII: $4 \%$ vs. $7 \%$, and

- stage cIII: 5 vs.17\%.

Noteworthy, about $10 \%$ of the local recurrences occurred beyond 5 years, indicating the necessity of a longer follow-up. In both trials similar quality assurance for surgery and pathology were used as in the 
Strahlenther Onkol 2013 · 189:105-110 DOI 10.1007/s00066-012-0299-5

๑) Springer-Verlag Berlin Heidelberg 2013

\section{M.L. Sautter-Bihl $\cdot$ W. Hohenberger $\cdot$ R. Fietkau $\cdot$ C. Rödel $\cdot$ H. Schmidberger $\cdot$ R. Sauer Rectal cancer. When is the local recurrence risk low enough to refrain from the aim to prevent it?}

\section{Abstract}

Recently, preliminary results of the OCUM study (optimized surgery and MRI-based multimodal therapy of rectal cancer) were published and raised concern in the scientific community. In this observational study, the circumferential resection margin status assessed in preoperative MRI (mrCRM) was used to decide for either total mesorectal excision (TME) alone or neoadjuvant radiochemotherapy (nRCT). In contrast to current guidelines, neither T3 stage (with negative (RM) nor clinically positive lymph nodes were an indication for nRCT. Pathologically node-positive patients received chemotherapy (ChT). Overall, 230 patients were included, of whom 96 CRM-positive patients received
$\mathrm{nRCT}$. The CRM was accurately predicted in $\mathrm{MRI}$, the rate of mesorectal plane resection was high. Recurrence rates have not yet been reported, but an impressive rate of downstaging for both $\mathrm{T}$ and $\mathrm{N}$ stage after $\mathrm{nRCT}$ was observed, while acute side effects were minimal. Nonetheless, the authors conclude that a substantial number of patients could be "spared severe radiation toxicity" and propagate their concept for prospectively replacing current guidelines. This is based on the hypothesis that CRM is a valid surrogate parameter for the risk of local recurrence and in case of a negative CRM, $\mathrm{nRCT}$ becomes dispensable. Moreover, it is assumed that lymph node status is no more relevant. Both as- sumptions are a contradiction to recent data from randomized studies as specified below. As 5-year locoregional recurrence rate (LRR) of only of $5-8 \%$ and $<5 \%$ in low risk rectal cancer can be achieved by the addition of RT, the noninferiority of surgery alone can not be presumed unless the expected 5 -year LRR is $\leq 5-8 \%$, whereas any excess of this range renders the study design inacceptable. Unless a publication explicitly specifies 5-year LRR, results are not exploitable for clinical decisions.

\section{Keywords}

Surgery · Radiation therapy · Neoadjuvant therapy · Radiochemotherapy · Treatment outcome

\section{Rektumkarzinom. Wann ist das Lokalrezidivrisiko so niedrig, dass es nicht mehr beachtet werden muss?}

\section{Zusammenfassung}

Kürzlich wurden vorläufige Ergebnisse einer Studie über "optimierte Chirurgie und MRTbasierte multimodale Therapie des Rektumkarzinoms (OCUM)“ publiziert, deren Interpretation unter Radioonkologen mit Bedenken zur Kenntnis genommen wurde. In dieser Beobachtungsstudie wurde anhand des präoperativen MRI der zu erwartende zirkumferentielle Resektionsrand (mrCRM) bewertet und daraufhin die Entscheidung getroffen, entweder eine alleinige totale mesorektale Exzision (TME) oder eine neoadjuvante Radiochemotherapie (nRCT) durchzuführen. Im Gegensatz zu den geltenden Leitlinien waren weder ein T3-Stadium (mit negativem CRM) noch bildmorphologisch positive Lymphknoten (LK) eine Indikation zur neoadjuvanten Therapie. Bei pathologisch positiven LK erfolgte eine Chemotherapie. Insgesamt wurden 230 Patienten in die Studie eingeschlossen, von denen 96 CRM-positive Patienten eine $\mathrm{nRCT}$ erhielten. Der CRM wurde im MR überwiegend richtig eingeschätzt, die chirurgische Qualität (mesorektale Resektionsebene) war hoch. Rezidivraten wurden nicht angegeben. Bei einem großen Prozentsatz der Patienten mit nRCT wurde jedoch ein Downstaging sowohl hinsichtlich der Tumorgröße als auch des Lymphknotenstatus beschrieben. Dabei traten nur wenige akute $\mathrm{Ne}$ benwirkungen auf. Dennoch kamen die Autoren zu dem Schluss, dass einer erheblichen Anzahl von Patienten die „schwere Radiotoxizität" erspart werden könne und sehen ihr Konzept der mrCRM als Option, zukünftig die Indikationsstellung der Leitlinien zu ersetzen. Dem wird die Hypothese zugrunde gelegt, dass der CRM ein zuverlässiger Surrogatparameter für die Vorhersage des Lokalrezidivrisikos darstelle und im Falle eines negativen CRM, die neoadjuvante Therapie entbehrlich sei. Darüber hinaus wird vorausgesetzt, dass der Lymphknotenstatus irrelevant für die lokale Tumorkontrolle sei. Beide
Annahmen stehen im Widerspruch zu jüngeren Daten mehrerer randomisierter Studien. Da in Kombination mit der Strahlentherapie 5-Jahres-Lokalrezidivraten (LRR) von 5-8\%, bei "Low-risk"-Patienten sogar von $<5 \%$ erzielt werden, ist zu fordern, dass eine Gleichwertigkeit der alleinigen Operation nur dann zu postulieren ist, wenn die zu erwartetende 5-Jahres-LRR ebenfalls $\leq 5-8 \%$ beträgt. Jedes Überschreiten dieses Schwellenwerts weist auf ein inakzeptables Studiendesign hin. Insbesondere können nur dann klinische Schlussfolgerungen aus einer Studie gezogen werden, wenn die 5-Jahres-LRR angegeben werden.

\section{Schlüsselwörter}

Operation · Strahlentherapie $\cdot$ Neoadjuvante Therapie - Radiochemotherapie . Behandlungserfolg
MERCURY study, disproving the assumption that the advent of proper TME may have overruled the significance of optimizing local control.

Intriguingly, in a recent methodological analysis of studies published on the accuracy of pretreatment MRI to predict negative from positive CRM in the operative specimen (including the MERCURY data), the authors concluded that "MRI cannot predict tumour involvement of a CRM" [5]. In contrast, the meta-analysis of Al-Sukhni assessed a specificity of $94 \%$ [1].

\section{Is lymph node status no longer related to local failure risk in the era of TME?}

The OCUM study does not only omit nRCT but replaces postoperative RCT by chemotherapy alone in node-positive patients irrespective of the number of affected nodes [42]. This is based on the hypothesis that TME provides complete re- 
moval of the lymphatic drainage upwards and therefore regional lymph nodes (except, lateral pelvic nodes) would no longer remain as origin of LR [17].

In an article by Hermanek et al. [17], however, a 33\% LRR was reported for $\mathrm{pN} 2$ patients after surgery alone. Moreover, a recently published pooled analysis of five European randomized studies, comparing different preoperative radiotherapy schedules confirmed that lymph node status was a significant predictive factor not only for distant metastases and survival, but also for local recurrences [44].

Evidence further arises that RT may not only improve local control, but also increase survival, especially in node positive patients. The MERCURY group observed that patients with suspected lateral nodes in MRI had a significantly worse 5-year DFS than those with negative findings when treated with surgery alone ( $31 \%$ vs. $76 \%$ ), while no impact on DFS was seen in patients who underwent nRCT [23].

The MRC-CR07 trial used postoperative chemotherapy for stage III patients; nonetheless, LR was $15.4 \%$ in the primary surgery group vs. only $7.4 \%$ after pre-irradiation [40]. In a further publication analyzing the plane of surgery in the MRCCR07 patients, Quirke described positive lymph nodes as the most important independent risk factor for local recurrence (HR 1.78, $\mathrm{p}<0.0001 ;$ [ 31$]$ ). Thus, the data of this trial suggest that chemotherapy alone is less effective for eradication of lymph node metastases, whereas RT halves the LRR in this subgroup.

The strongest evidence for the impact of RT on prognosis in lymph node positive patients can be derived from the Dutch TME trial: node-positive patients with a negative PCRM, treated with TME alone, had a 10 -year OAS of $57 \%$ in stage II vs. only $40 \%$ in stage III. In contrast, irradiated patients had an almost identical 10 -year OAS (51\% and 50\%) [45]. These findings indicate that even in the era of quality-assured TME, the negative impact of positive lymph nodes on local control and survival can, at least partly, be compensated by preoperative RT.

These findings corroborate the hypothesis that improved local tumor control is not merely prevention of local re- currence, but furthermore sterilization of subclinical disease and thus "stopping metastases at their source" [16].

The concept of MRI-based omission of preoperative RT in CRM-negative patients irrespective of nodal status will exclude node-positive patients from any RT. Although the landmark CAO/ARO/AIO94 trial demonstrated that postoperative RCT is less effective and more toxic than preoperative RCT [37], it seems doubtful whether the total omission of RT can be compensated by adjuvant $\mathrm{ChT}$ alone in stage III patients.

\section{Should the level of evidence be neglected?}

The Scandinavian Surgical Outcomes Research Group recently commented on controversies in rectal cancer management as follows:

In surgery there is a tendency to disregard the normal scientific methods of evaluation, whereas in medicine it is fully established that a new drug cannot be used without formal assessment according to strict scientific principles [35].

The authors of the OCUM study [42] argue that

guidelines are increasingly recommending MRI as the basis for the indication of $n R C T$ even though a prospective study has not been conducted until now.

Actually, besides the German S3 guideline [38], the recently updated European [39], American [24], Canadian [7], and English [25] guidelines indeed advocate MRI use for preoperative staging but none of these guidelines recommends basing the further treatment decision on the MRI prediction of a positive CRM alone.

Even though the MERCURY data have brought promising perspectives for the management of rectal cancer, the question remains whether and how soon data from observational studies using a surrogate (mrCRM) of a surrogate parameter (pCRM) should be adopted into routine practice. Observational data will not provide an equally solid level of evidence compared to those of randomized tri- als that built the background for current guidelines.

It remains highly desirable to better select those patients for neoadjuvant treatment who are most likely to benefit and to consider primary surgery in subgroups with low anticipated risk factors $[8,11,18]$. On the other hand, additional risk features such as extramural vascular invasion $[25,41]$ and mucinous carcinoma may contribute to the treatment decision [28]. A standardized international classification for the "good, the bad, and the ugly" [11], i.e., the different risk groups would be helpful to assure comparability of different treatment approaches and better outweigh risk reduction against side effects. Late toxicity In the $\mathrm{CAO} / \mathrm{ARO} / \mathrm{AIO}$ trial was diarrhea or small bowel obstruction in $9 \%$, of whom $2 \%$ required reoperation. Bladder problems were observed in $2 \%$ [36]. In the TME trial, bowel dysfunction impairing daily life occurred in $34 \%$, daily incontinence in $14 \%$ [30]. Radiation toxicity has been substantially reduced since data of large studies analyzing the pattern of local failure permitted a reduction of field size [26]. Innovative techniques such as intensity-modulated (IMRT; [20]) and image-guided (IGRT; [13]) radiotherapy will further permit adverse effects to be minimized. Individual response and toxicity scores [47] may be another promising tool and new concepts for systemic treatment are warranted for patients at risk of distant metastases $[6,33,34,46]$.

Doubtlessly, quality optimization of established procedures, such as high resolution MRI or TME in the mesorectal plane, should promptly be translated into clinical routine. However, major changes of treatment that bear a potential risk of increasing recurrence should preferentially be evaluated in randomized trials, providing standardized specifications for each phase of treatment-and not leaving therapy to the discretion of the treating institution! The disadvantage of such stricter rules may be a lower rate of accru$\mathrm{al}$ and thus a longer interval until results are available. However, only mature results should lead to a change of practice. A major concern would be the uncritical adoption of a treatment requiring highest standards of quality-assured multimod- 
al procedures outside specialized centers with trained and experienced teams [18, 19]. Accounting for the large number of patients with rectal cancer, even small incremental changes in treatment policy may impact thousands of individuals. Finally, recent data suggest $[40,45]$ that best surgery yields highest benefit of radiotherapy; thus, the strength of each discipline reinforces the other [32].

\section{Corresponding address}

\section{Prof. Dr. M.L. Sautter-Bihl}

Klinik für Radioonkologie und Strahlentherapie, Städtisches Klinikum Karlsruhe

Moltkestr. 90, 76133 Karlsruhe

Germany

marie-luise.sautter-bihl@klinikum-karlsruhe.de

Conflict of interest. On behalf of all authors, the corresponding author states that there are no conflicts of interest.

\section{References}

1. Al-Sukhni E, Milot L, Fruitman M et al (2012) Diagnostic accuray of MRI for assessment of T category, lymph node metastases, and circumferential resection margin involvement in patients with rectal cancer: a systematic re-view and meta-analysis. Ann Surg Oncol 19:2212-2223

2. Bouchard P, Efron J (2010) Management of recurrent rectal cancer. Ann Surg Oncol 17:1343-1356

3. Bosset JF, Calais G, Mineur L et al (2005) Enhanced tumorocidal effect of chemotherapy with preoperative radiotherapy for rectal cancer: preliminary results-EORTC 22921. J Clin Oncol 23:5620-5627

4. Bujko K, Nowacki MP, Nasierowska-Gunmejer A (2004) Sphincter preser-vation following preoperative radiotherapy for rectal cancer: report of a randomised trial comparing short-term radiotherapy vs. conventionally fractionated radiochemotherapy. Radiother Oncol 72:15-24

5. Dent OF, Chapuis PH, Haboubi N, Bokey L (2011) Magnetic resonance imaging cannot predict histological tumour involvement of a circumferential surgical margin in rectal cancer. Colorectal Dis 13:974-981

6. Dewdney A, Cunningham D, Tabernero J et al (2012) Multicenter randomized phase II clinical trial comparing neoadjuvant oxaliplatin, capecitabine, and preoperativ radiotherapy with or without cetuximab followed by total mesorectal excision in patients with high-risk rectal cancer. J Clin Oncol 30:1620-1627

7. Di Valentin, Alam Y, Ali-Alsharm A (2012) Eastern Canadian colorectal cancer consensus conference: application of new modalities of staging and treatment of gastrointestinal cancers. Curr Oncol 19:169-174

8. Fietkau R (2010) Rectal cancer: quo vadis, neoadjuvant and adjuvant (chemo) radiotherapy? Int J Colorectal Dis $25 \cdot 285-287$
9. Folkesson J, Birgisson H, Pahlman L et al (2005) Swedish Rectal Cancer Trial: long lasting benefits from radiotherapy on survivial and local recurrence rate. J Clin Oncol 23:5644-5650

10. Gérard JP, Conroy T, Bonnetain F et al (2006) Preoperative radiotherapy with or without concurrent fluorouracil and leucovorin in T3-4 rectal cancers: results of FFCD 9203. J Clin Oncol 24:4620-4625

11. Glimelius B (2012) Multidisciplinary treatment of patients with rectal cancer: development during the past decades and plans for the future. Ups J Med Sci 117:225-236

12. Glynne-Jones R, Mawdsley S, Pearce T, M. Buyse M (2006) Alternative clinical end points in rectal cancer-are we getting closer? Annals Oncol 17:1239-1248

13. Gwynne S, Webster R, Adams R et al (2012) Imageguided radiotherapy for rectal cancer: a systematic review. Clin Oncol (R Coll Radiol) 24:250-260

14. Gunderson LL, Sargent DJ, Tepper JE et al (2004) Impact of $\mathrm{T}$ and $\mathrm{N}$ stage and treatment on survival and relapse in adjuvant rectal cancer: a pooled analysis. J Clin Oncol 22:1785-1796

15. Heald RJ, Ryall RD (1986) Recurrence and survival after total mesorectal excision for rectal cancer. Lancet 28:1479-1482

16. Hellmann S (1997) Stopping metastases at their source. N Engl J Med 337:996-997

17. Hermanek P, Merkel S, Fietkau R et al (2010) Regional lymph node metastasis and locoregional recurrence of rectal carcinoma in the era of TNM surgery. Implications for treatment decisions. Int J Colorectal Dis 25:359-368

18. Hermanek $P$, Hohenberger W, Fietkau R, Rödel C (2011) Individualized magnetic resonance imaging-based neoadjuvant chemoradiation for middle and lower rectal carinoma. Colorectal Dis 13:39-47

19. Hohenberger W, Merkel S, Hermanek P (2012) Volume and outcome in rectal cancer surgery: the importance of quality management. Int $J$ Colorectal Dis. Nov 10 [Epub ahead of print]

20. Jabbour SK, Patel S, Hermann JM et al (2012) Intensity-modulated radia-tion therapy for rectal carcinoma can reduce breaks and emergency department visits. Int J Surg Oncol 2012:891067 Epub 2012 Aug 13

21. Kosinski L, Habr-Gama A, Ludwig K et al (2012) Shifting concepts in rectal cancer management. CA Cancer J Clin 62:173-202

22. Maurer CA, Mattiello D, Duwe J et al (2012) Oncological short-term effects and adverse events of MRI-guided selective neoadjuvant radiochemother-apy for rectal cancer. Anticancer Res 32:17211728

23. MERCURY Study Group, Shihab OC, Taylor F (2011) Relevance of mag-netic resonance imaging-detected pelvic sidewall lymph node involvement in rectal cancer. Br J Surg. 98:1798-1804

24. NCCN clinical practice guidelines in oncology. Rectal Cancer (2012) J National Comprehensive Cancer Network Version 3.2012

25. NICE clinical guideline 131 (2011) The diagnosis and management of colorectal cancer. Issued: November 2011 guidance.nice.org.uk/cg131. Accessed 12 December 2012

26. Nijkamp J, Kusters M, Beets-Tan RG et al (2011) Three-dimensional analy-sis of recurrence patterns in rectal cancer: the cranial border in hypofractionated preoperative radiotherapy can be lowered. Int J Radiat Oncol Biol Phy 80:103-110
27. Ngan SY, Burmeister B, Fisher RJ et al (2012) Randomized trial of short-course radiotherapy versus long-course chemoradiation comparing rates of local recurrence in patients with $\mathrm{T} 3$ rectal cancer: Trans-Tasman Radiation Oncology Group Trial 01.04. J Clin Oncol 30:3827-33

28. Oberholzer K, Menig M, Kreft A et al (2012) Rectal cancer: mu-cinous carcinoma on magnetic resonance imaging indicates poor response to neoadjuvant chemoradiation. Int J Radiat Oncol Biol Phys. 82:842-848

29. Patel UB, Taylor F, Blomqvist L et al (2011) Magnetic resonance imaging-detected tumor response for locally advanced rectal cancer predicts survival outcomes: MERCURY experience. J Clin Oncol 29:3753-3760

30. Peeters KC, van de Velde CJ, Leer JW (2005) Late side effects of short-course preoperative radiotherapy combined with total mesorectal excision for rectal cancer: increased bowel dysfunction in irradiated patients-A Dutch Colorectal Cancer Group Study. J Clin Oncol 23:6199-6206

31. Quirke P, Steele R, Monson J et al (2009) Effect of the plane of surgery achieved on local recurrence in patients with operable rectal cancer: a prospective study using data from the MRC CRO7 and NCIC-CTG C016 ran-domised clinical trial. Lancet 373:821-828

32. Rödel C, Sauer R, Fietkau R (2009) Die Rolle der Magnetresonanztomo-graphie für die Indikationsstellung zur präoperativen Therapie beim Rektumkarzinom. Strahlenther Onkol 185:488-492

33. Rödel C, Arnold D, Becker H et al (2010) Induction chemotherapy before chemoradiotherapy and surgery for locally advanced rectal cancer: is it time for a randomized phase III trial? Strahlenther Onkol 186:658-664

34. Rödel C, Liersch T, Becker H et al (2012) Preoperative chemoradiotherapy and postoperative chemotherapy with fluorouracil and oxaliplatin versus fluorouacil alone in locally advanced rectal cancer: initial results of the German CAO/ARO/AOI-04 randomised phase 3 trial. Lancet Oncol 13:679-687

35. Rosenberg J, Fischer A, Haglind E† (2012) Current controversies in colorectal surgery: the way to resolve uncertainty and move forward. Colorectal Dis 14:266-269

36. Sauer R, Becker H, Hohenberger W et al (2004) Preoperative versus postoperative chemoradiotherapy for rectal cancer. N Engl J Med 351:1731-1740

37. Sauer R, Liersch T, Merkel S et al (2012) Preoperative versus postoperative chemoradiotherapy for locally advanced rectal cancer: results of the german CAO/ARO/AIO-94 randomized phase III trial after a median follow-up of 11 years. J Clin Oncol 30:1926-1933

38. Schmiegel W, Pox C, Reinacher-Schick A et al (2010) S3 guidelines for colorectal carcinoma: results of an evidence-based consensus conference on February 6/7, 2004 and June 8/9, 2007 (for the topics IV, VI and VII). Z Gastroenterol 48:65-136

39. Schmoll HJ, van Cutsem E, Stein A et al (2012) ESMO Consensus Guidelines for management of patients with colon and rectal cancer. A personalized approach to clinical decision making. An Oncol 23:2479-2516

40. Sebag-Montefiore D, Stephens RJ, Steele R et al (2009) Preoperative radiotherapy versus selective postoperative chemoradiotherapy in patients with rectal cancer (MRC CR07 and NCIC-CTG C016): a multicentre, randomised trial. Lancet 373:811-820 


\section{Editorial}

41. Smith NJ, Barbachano Y, Norman AR et al (2008) Prognostic significance of magnetic resonance imaging-detected extramural vascular invasion in rectal cancer. Br J Surg 95:229-236

42. Strassburg J, Ruppert R, Ptok H et al (2011) MRIbased indications for neoadjuvant radiochemotherapy in rectal carcinoma: interim results of a prospective multicenter observational study. Ann Surg Oncol 18:2790-2799

43. Taylor F, Quirke Ph, Heald RJ et al (2011) Preoperative high-resolution magnetic resonance imaging can identify good prognosis stage I, II, and III rectal cancer best managed by surgery alone. Ann Surg 253:711-719

44. Valentini V, van Stiphout RG, Lammering $G$ et al (2011) Nomograms for predicting local recurrence, distant metastases, and overall survival for patients with locally advanced rectal cancer on the basis of European randomized clinical trials. J Clin Oncol 29:3163-3172

45. Van Gijn W, Marijnen AM, Nagtegaal ID et al (2011) Preoperative radiotherapy combined with total mesorectal excision for resectable rectal can-cer: 12-year follow-up of the multicentre, randomised controlled TME trial. Lancet Oncol 12:575-582

46. Weiss C, Arnold D, Della K et al (2010) Preoperative radiotherapy of advanced rectal cancer with capecitabine and oxaliplatin with or without cetuximab: A pooled analysis of three prospective phase I-II trials. Int J Ra-diat Oncol Biol Phys 78:472-478

47. Wolff HA, Hennies S, Herrmann MK et al (2011) Comparison of the micronucleus and chromosome aberration techniques for the documentation of cytogenetic damage in radiochemotherapy-treated patients with rectal cancer. Strahlenther Onkol 187:52-58 